\title{
Pharmacotherapy in the cardiac catheterization laboratory: evolution and recent developments
}

\author{
This article was published in the following Dove Press journal: \\ Therapeutics and Clinical Risk Management \\ 21 October 2014 \\ Number of times this article has been viewed
}

\section{Guramrinder S Thind \\ Raunak Parida' \\ Nishant Gupta ${ }^{2}$}

'SDM College of Medical Sciences and Hospital, Dharwad, Karnataka, India; ${ }^{2}$ University of Texas at Houston, Houston, TX, USA
Correspondence: Guramrinder S Thind SDM College of Medical Sciences and Hospital, Manjushree Nagar, Sattur, Dharwad - 580009, Karnataka, India Tel +9l 8146340787

Email gsthind 105@gmail.com

\begin{abstract}
Many recent innovations have been made in developing new antiplatelet and anticoagulant drugs in the last few years, with a total of nine new antithrombotic drugs approved by the Food and Drug Administration after the year 2000. This has revolutionized the medical therapy given to manage acute coronary syndrome and support cardiac catheterization. The concept of dual antiplatelet therapy has been emphasized, and clopidogrel has emerged as the most-popular second antiplatelet drug after aspirin. Newer P2 $\mathrm{Y}_{12}$ inhibitors like prasugrel and ticagrelor have been extensively studied and compared to clopidogrel. The role of glycoprotein (Gp) IIb/IIIa inhibitors is being redefined. Other alternatives to unfractionated heparin have become available, of which enoxaparin and bivalirudin have been studied the most. Apart from these, many more drugs with novel therapeutic targets are being studied and are currently under development. In this review, current evidence on these drugs is presented and analyzed in a way that would facilitate decision making for the clinician. For this analysis, various high-impact clinical trials, pharmacological studies, meta-analyses, and reviews were accessed through the MEDLINE database. Adopting a unique interdisciplinary approach, an attempt has been made to integrate pharmacological and clinical evidence to better understand and appreciate the pros and cons of each of these classes of drugs.
\end{abstract}

Keywords: acute coronary syndrome, anticoagulants, antiplatelets, percutaneous coronary intervention

\section{Introduction}

The pharmacology of hemostasis and thrombosis has been rapidly evolving, with six new drugs approved by the Food and Drug Administration (FDA) after 2009. The evolution of antithrombotic drugs has been gradual in the 20th century, with aspirin, unfractionated heparin (UFH), and warfarin being the only ones available for the most part of the century. The last decade of the century saw some brisk developments with the introduction of thienopyridines (ticlopidine in 1991 and clopidogrel in 1997) and low-molecular-weight heparins (LMWHs) (enoxaparin in 1993 and dalteparin in 1994). Toward the end of the decade, the glycoprotein (Gp) IIb/IIIa inhibitors were introduced. The dawn of the 21 st century marked an explosion of new discoveries with drugs like synthetic pentasaccharides (fondaparinux), direct thrombin inhibitors, and direct Xa inhibitors. ${ }^{1}$ These drugs are listed in Table 1.

With this wide selection of therapeutic options at our disposal, it is only natural to expect that a lot of research has been done in defining and contrasting the safety and efficacy profiles of these drugs. This discussion focuses on analyzing the various therapeutic options currently available to support percutaneous coronary intervention (PCI) and for managing acute coronary syndrome (ACS). The latest American College of Cardiology Foundation/American Heart Association (ACC/AHA) guidelines have 
Table I FDA-approved antiplatelet and anticoagulant drugs listed in order of their year of approval

\begin{tabular}{|c|c|c|c|c|c|}
\hline Number & Drug name & Class & Route & Year approved & Notes \\
\hline I & Heparin & Anticoagulant & IV & 1939 & Oldest drug in class. \\
\hline 2 & Warfarin & Anticoagulant & Oral & 1954 & First oral anticoagulant, no role in ACS. \\
\hline 3 & Aspirin & Antiplatelet & Oral & Late 1980s & Approved as analgesic in 1965 \\
\hline 4 & Ticlopidine & Antiplatelet & Oral & 1991 & Rarely used now because of side effects. \\
\hline 5 & Enoxaparin & Anticoagulant & SC/IV & 1993 & First LMWH. \\
\hline 6 & Dalteparin & Anticoagulant & SC/IV & 1994 & Only approved for UA/NSTEMI. \\
\hline 7 & Clopidogrel & Antiplatelet & Oral & 1997 & Most-popular second antiplatelet. \\
\hline 8 & Abciximab & Antiplatelet & IV & 1997 & First glycoprotein Ilb/llla inhibitor. \\
\hline 9 & Eptifibatide & Antiplatelet & IV & 1998 & Second glycoprotein Ilb/llla inhibitor. \\
\hline 10 & Tirofiban & Antiplatelet & IV & 1999 & Third glycoprotein Ilb/llla inhibitor. \\
\hline 11 & Tinzaparin & Anticoagulant & SC/IV & 2000 & No role in ACS. \\
\hline 12 & Bivalirudin & Anticoagulant & IV & 2000 & Approved for use before $\mathrm{PCl}$. \\
\hline 13 & Argatroban & Anticoagulant & IV & 2000 & Only approved for patients with HIT. \\
\hline 14 & Fondaparinux & Anticoagulant & SC & 2001 & First and only synthetic pentasaccharide. \\
\hline 15 & Prasugrel & Antiplatelet & Oral & 2009 & First alternative to clopidogrel. \\
\hline 16 & Dabigatran & Anticoagulant & Oral & 2010 & No role in ACS. \\
\hline 17 & Ticagrelor & Antiplatelet & Oral & 2011 & Second alternative to clopidogrel. \\
\hline 18 & Rivaroxaban & Anticoagulant & Oral & 2011 & No role in ACS. \\
\hline 19 & Apixaban & Anticoagulant & Oral & 2012 & No role in ACS. \\
\hline 20 & Vorapaxar & Antiplatelet & Oral & 2014 & Introduced triple antiplatelet therapy. \\
\hline
\end{tabular}

Abbreviations: ACS, acute coronary syndrome; FDA, Food and Drug Administration; HIT, heparin induced thrombocytopenia; IV, intravenous; LMWH, low-molecularweight heparin; PCI, percutaneous coronary intervention; SC, subcutaneous; UA/NSTEMI, unstable angina/non-stent thrombosis segment elevation myocardial infarction.

been referred to for the purpose of the discussion (unless otherwise specified). ${ }^{2}$

\section{Methods}

The MEDLINE database was primarily explored via PubMed to search and access clinical trials, studies, meta-analyses, and reviews relevant to our discussion. The registry ClinicalTrials.gov was also referred to while analyzing the various clinical trials.

Since the discussion is broad-based, no uniform inclusion/exclusion criteria were defined in selecting the studies to be included in this review. An attempt has been made to select studies with the highest impact in terms of their reputation as well as their general influence on the trends in interventional pharmacology. A total of 30 clinical trials have been discussed and/or mentioned in this review. No original meta-analysis has been performed in this review. Any caveat, potential bias, or limitation, if present, has been mentioned along with the discussion of the individual studies.

\section{Overview of the pharmacology of currently available drugs}

Antiplatelets and anticoagulants affect the two main limbs of hemostasis: platelet reactivity and the coagulation cascade. Platelets and clotting factors form an interdependent, intricately interlinked, and almost sequential effector mechanism of hemostasis. Platelet adhesion, activation, and aggregation are the seminal steps of hemostasis. Although the coagulation cascade develops on a scaffolding of the platelet plug, platelet activation and aggregation are strongly facilitated by clotting factors: most prominently thrombin. Thrombin is a protein with multiple physiological roles involving various systems. This exemplifies the fact that multiple physiological pathways including the coagulation cascade, fibrinolytic pathway, kinin pathway, and the complement pathway are all interlinked.

Arterial and venous thrombi have traditionally been considered to be unique in terms of pathophysiology and clot content. Arterial thrombi are formed secondary to some form of endothelial dysfunction (eg, atherosclerotic plaque) in an environment where the shear stress is high. Such an environment leads to the formation of a platelet-rich clot with minimal activation of the coagulation cascade: sometimes referred to as the white thrombus. On the other hand, venous clots form in undamaged veins where the blood flow and shear stress are low. This allows adequate activation of the coagulation cascade that causes entrapment of red blood cells in the mesh, thereby forming a fibrin and red-cell rich red thrombus. ${ }^{3}$

Based on this background, it is easy to comprehend why antiplatelet therapy is predominantly used to prevent arterial thrombosis (eg, ACS) and not venous thrombosis (eg, deep venous thrombosis). However, these distinctions are not at all absolute, and experimental evidence supports the use of 
adjunctive antiplatelet therapy for the management of venous thrombosis, thereby reinforcing the importance of undeniable crosstalk between the two systems. ${ }^{4}$

Each of these classes of drugs exploits a unique step in the normal hemostatic processes, which is illustrated in Figures 1 and 2. Other special characteristics of the pharmacology of individual drugs are discussed in the respective sections.

\section{Current literature on the new drugs}

Extensive research has been done to test the efficacy and safety profiles of the newer drugs and compare them with the current standard of treatment. The current understanding of the various characteristics of the available drugs and some of the pressing issues in interventional pharmacology is being discussed.

Although the role of aspirin in ACS is paramount and a class I indication as per the current guidelines, ${ }^{2}$ the choice of second antiplatelet drug after aspirin has been evolving. P2 $\mathrm{Y}_{12}$ inhibitors are a diverse class of drugs comprising thienopyridines (clopidogrel and prasugrel) and ticagrelor. A P2 $\mathrm{Y}_{12}$ inhibitor is given along with aspirin for the acute management of ACS as well as for maintenance therapy postPCI, to provide a more complete antiplatelet effect.

\section{Clopidogrel: optimum loading dose}

Various trials have shown the benefit of adding clopidogrel to aspirin in ACS patients, and it has emerged as the most

\section{Platelet activation}

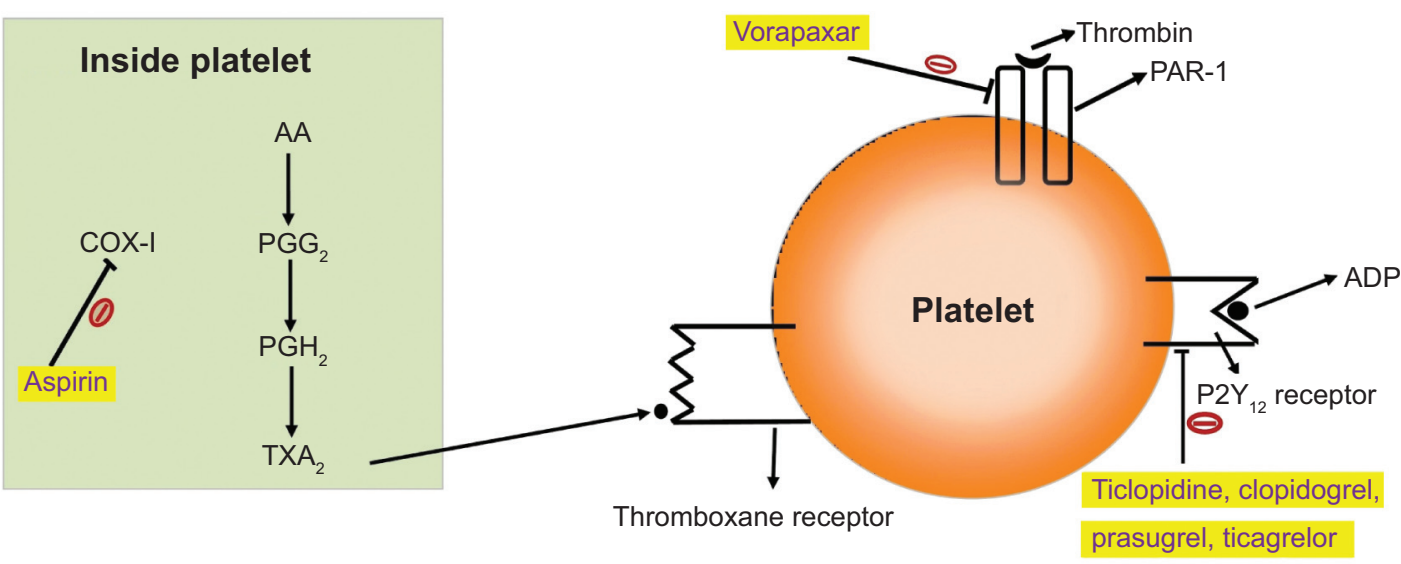

Fibrinogen serves to "cross-link" platelets via the gpllb-IIla complex

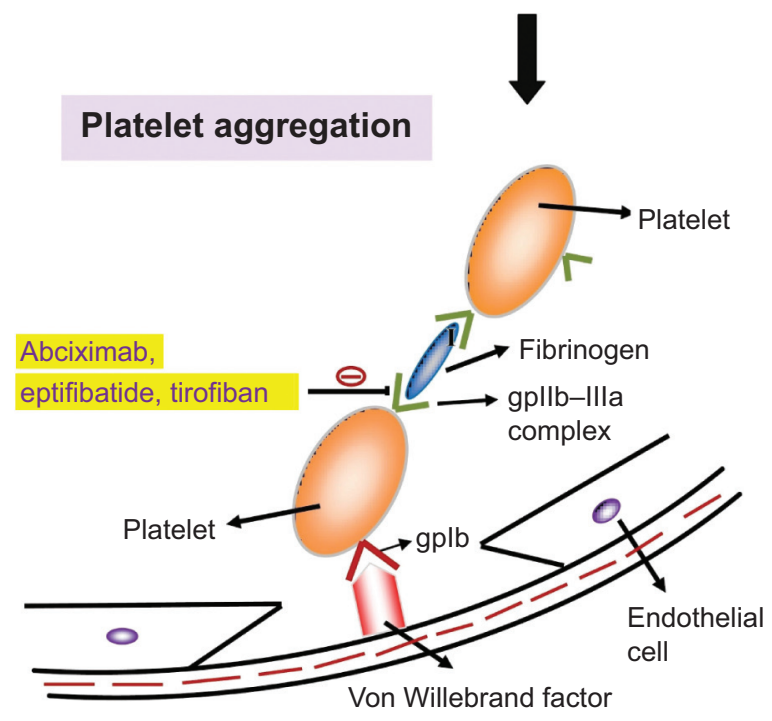

Figure I An overview of the mechanism of action of antiplatelet drugs, showing their effects on various steps of platelet activation and aggregation.

Abbreviations: AA, arachidonic acid; ADP, adenosine diphosphate; COX, cyclooxygenase; gplb, glycoprotein lb; gpllb-Illa, glycoprotein IIb/Illa; PAR-I, platelet-activated receptor I; $\mathrm{PGG}_{2}$, prostaglandin $\mathrm{G} 2 ; \mathrm{PGH}_{2}$, prostaglandin $\mathrm{H} 2$; $\mathrm{TXA}_{2}$, thromboxane $\mathrm{A} 2$. 


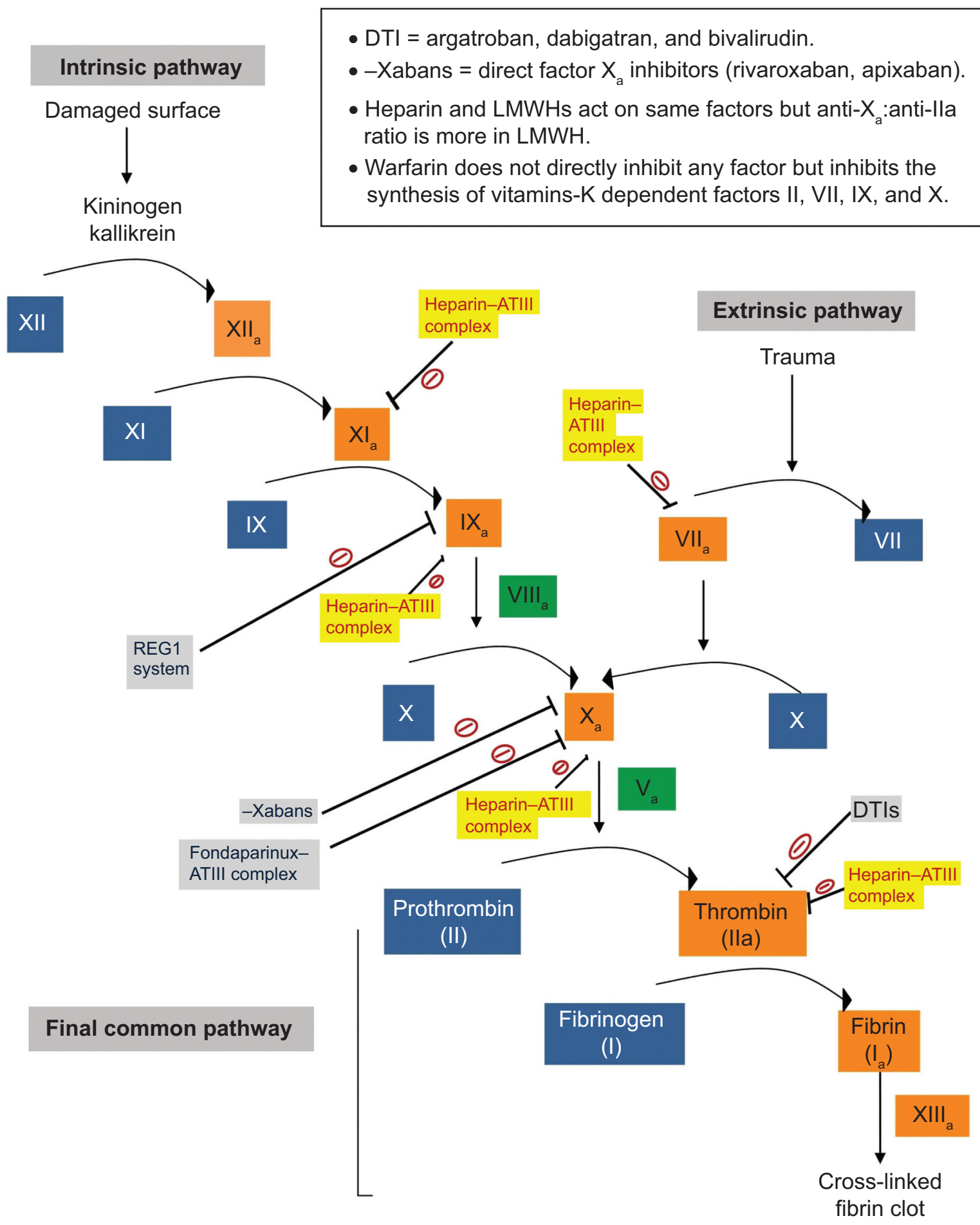

Figure 2 An overview of mechanism of action of the anticoagulant drugs, showing their effects on various steps in the normal coagulation cascade. Abbreviations: ATIII, antithrombin III; DTI, direct thrombin inhibitor; LMWH, low-molecular-weight heparin.

common choice for the second antiplatelet agent after aspirin. ${ }^{5,6}$ Many studies have been done to determine the optimum loading dose of clopidogrel for patients undergoing PCI. The most prominent among these was the CURRENT/ OASIS7 trial enrolling ACS patients planned to undergo PCI. Incidence of primary outcomes (cardiovascular death, myocardial infarction [MI], or stroke at 30 days) was similar in both double-dose $(600 \mathrm{mg})$ and standard-dose groups (300 mg) (4.2\% versus 4.4\%; hazard ratio [HR] $=0.94 ; 95 \%$ confidence interval $[\mathrm{CI}]: 0.83-1.06 ; P=0.30$ ). In the subset of patients undergoing $\mathrm{PCI}$, the incidence of primary events was lower with double-dose clopidogrel (3.9\% versus $4.5 \%$; 
$\mathrm{HR}=0.85 ; 95 \% \mathrm{CI}: 0.74-0.99 ; P=0.39)$. Post hoc analysis revealed a reduction in definite stent thrombosis (ST) in the double-dose group (1.6\% versus $2.3 \%$; HR=0.68; $95 \%$ CI: $0.55-0.85 ; P<0.001)$. Incidence of major bleeding was slightly higher in the double-dose group $(2.5 \%$ versus $2.0 \%$; $\mathrm{HR}=1.24$; 95\% CI: $1.05-1.46 ; P=0.01)$. Overall, the results were not entirely conclusive.

However, there have been other trials and meta-analyses done to address this issue, and double-dose regimen has invariably been proven to be superior. ${ }^{8,9}$ Siller-Matula et al performed a meta-analysis studying the efficacy of the two clopidogrel doses in patients undergoing PCI, at 1 month after start of therapy. ${ }^{10}$ It showed a $34 \%$ relative risk (RR) reduction of major adverse cardiac events (MACE) in the doubledose group $(\mathrm{RR}=0.66$; 95\% CI: $0.52-0.84 ; P<0.001)$ with no increase in risk of major bleeding in the group $(\mathrm{RR}=0.91$; 95\% CI: $0.73-1.15 ; P=0.44)$.

von Beckerath et al in their pharmacological study enrolling 60 patients studied three different doses of clopidogrel: $300 \mathrm{mg}, 600 \mathrm{mg}$, and $900 \mathrm{mg} .{ }^{11}$ Compared to $300 \mathrm{mg}$, the $600 \mathrm{mg}$ dose was shown to achieve a higher plasma concentration $(P \leq 0.03)$ and an enhanced inhibition of adenosine diphosphate (ADP)-induced platelet aggregation 4 hours after drug administration $(P=0.01$ and $P=0.004$ for 5 and $20 \mu \mathrm{mol} / \mathrm{L}$ ADP, respectively). However, intestinal absorption was proposed to act as a bottleneck in doses higher than $600 \mathrm{mg}$. The $900 \mathrm{mg}$ dosing failed to increase plasma concentration $(P \geq 0.38)$ or inhibit ADP-induced platelet aggregation 4 hours after drug administration $(P=0.59$ and $P=0.39$ for 5 and $20 \mu \mathrm{mol} / \mathrm{L}$ ADP, respectively).

In a later study with a larger sample size $(\mathrm{N}=103)$ called the ALBION trial, Montalescot et al studied the pharmacology of different clopidogrel doses up to 24 hours after administration. ${ }^{12}$ They noted a uniform increment in the efficacy of higher doses (600 mg and $900 \mathrm{mg}$ ) of clopidogrel compared to the standard dose (300 mg). Thus, when compared to $600 \mathrm{mg}$, the $900 \mathrm{mg}$ dose was found to have a superior pharmacology. Higher doses had a faster onset as well as a greater maximal inhibition of platelet activity. The rates of hypo-responders were also decreased proportionately with higher doses $(P=0.20$ and $P=0.007$ for 5 and $20 \mu \mathrm{mol} / \mathrm{L} \mathrm{ADP}$, respectively).

\section{Clopidogrel versus newer $\mathrm{P}^{2} \mathrm{Y}_{12}$ inhibitors}

Two new P2 $\mathrm{Y}_{12}$ inhibitors have been approved by the FDA recently: prasugrel in 2009 and ticagrelor in 2011. The newer drugs offer definite benefits over clopidogrel.

\section{Pitfalls of clopidogrel}

When compared to the newer $\mathrm{P}_{2} \mathrm{Y}_{12}$ inhibitors, the antiplatelet action of clopidogrel has been described to be slow, modest, and variable. Pharmacological studies comparing these drugs have shown a delayed onset of activity and higher on-treatment platelet reactivity with clopidogrel. Another issue with clopidogrel is that of resistance and interpatient variability. Serebruany et al did an ex vivo platelet-function study recruiting both healthy volunteers and post-PCI, heart failure, and stroke patients. ${ }^{13}$ They demonstrated that the variability of response to clopidogrel follows a normal distribution, with the percentage of hypo-respondents and hyper-respondents ( \pm 2 standard deviations) in their study being $4.2 \%$ and $4.8 \%$, respectively.

Various mechanisms have been proposed to explain clopidogrel resistance such as drug interactions, $\mathrm{P} 2 \mathrm{Y}_{12}$ receptor variability, etc, but the one which has been studied the most is unfavorable metabolism. Both clopidogrel and prasugrel are prodrugs that have to be converted to their active metabolites. Hagihara et al in their study showed that $90 \%$ of clopidogrel was converted into an inactive acid metabolite. ${ }^{14}$ Interpatient variability also exists in the activity of microsomal enzymes responsible for the formation of its active metabolite, with CYP2C19 polymorphisms being studied the most. ${ }^{15}$ This explains the moderate efficiency and high variability of response to clopidogrel when compared to other drugs.

\section{Clopidogrel versus prasugrel}

The most prominent trial comparing these two drugs was the TRITON-TIMI 38 enrolling ACS patients undergoing PCI. ${ }^{16}$ The prasugrel group had a significantly reduced incidence of primary outcome (cardiovascular death, nonfatal MI, or nonfatal stroke): $4.7 \%$ versus $5.6 \%$ in clopidogrel group (HR=0.82; 95\% CI: $0.73-0.93 ; P<0.002)$.

The increased efficacy of prasugrel was at the expense of increased risk of bleeding. The incidence of non-coronary artery bypass grafting (CABG)-related TIMI (Thrombolysis In Myocardial Infarction) major bleed was $2.4 \%$ with prasugrel versus $1.8 \%$ with clopidogrel $(\mathrm{HR}=1.32 ; 95 \% \mathrm{CI}$ : $1.03-1.68 ; P=0.03)$. The prasugrel group had an increased incidence of both "life threatening" (1.4\% versus $0.9 \%$; $\mathrm{HR}=1.52 ; 95 \% \mathrm{CI}: 1.08-2.13 ; P=0.01)$ and "fatal" bleeding $(0.4 \%$ versus $0.1 \%$; $\mathrm{HR}=4.19 ; 95 \% \mathrm{CI}: 1.58-11.11$; $P=0.002$ ). Even though few patients underwent $\mathrm{CABG}$, the incidence of CABG-related bleeding was also found to be higher in the prasugrel group: (13.4\% versus 3.2\%; $\mathrm{HR}=4.73 ; 95 \% \mathrm{CI}: 1.90-11.82 ; P<0.001)$. Post hoc analysis revealed three high-risk groups: patients with a history of 
stroke/transient ischemic attack had a net harm from prasugrel, while elderly ( $>75$ years) and patients with body weight less than $60 \mathrm{~kg}$ had no net clinical benefit.

Many studies have shown the pharmacological superiority of prasugrel over clopidogrel. Brandt et al measured inhibition of platelet aggregation after administering prasugrel in healthy subjects, compared it to that of clopidogrel up to 24 hours, and found it to be significantly higher $(P<0.1) .{ }^{17}$ The peak inhibition of platelet aggregation for prasugrel was also higher $(P<0.001)$. The antiplatelet action of prasugrel was shown to be more rapid; time taken to reach $\geq 20 \%$ inhibition of platelet aggregation was 30 minutes for prasugrel and 1.5 hours for clopidogrel. This factor may have been responsible for a reduction in the rate of "early" MI (before day 3) in the TRITON-TIMI 38 trial (4.7\% with prasugrel versus $5.6 \%$ with clopidogrel; $P=0.01$ ). The antiplatelet activity of prasugrel is also more consistent. Jernberg et al studying aspirin-treated patients with coronary artery disease documented no nonresponders with prasugrel as compared to $45 \%$ in the clopidogrel group $(P=0.0007) .{ }^{18}$

\section{Clopidogrel versus ticagrelor}

Ticagrelor is the latest addition to the group of $\mathrm{P} 2 \mathrm{Y}_{12}$ inhibitors. It is chemically unique and is the first member of a new class of drugs known as cyclopentyl-triazolo-pyrimidines. The major trial designed to analyze the safety and efficacy of ticagrelor and compare it with clopidogrel was the PLATO trial enrolling 18,624 ACS patients in 43 countries. ${ }^{19}$ The incidence of primary endpoint (death from vascular causes, MI, or stroke) at 12 months was significantly lower in the ticagrelor group (9.8\% versus $11.7 \%$; $\mathrm{HR}=0.84 ; 95 \% \mathrm{CI} ; 0.77-0.92 ; P<0.001)$. On further statistical analysis, these benefits were found to be both short-term (0-30 days) and long-term (31-360 days), and in both ST segment elevation MI (STEMI) and unstable angina/non-STEMI (NSTEMI) patients; this was irrespective of whether PCI was done or not.

There was no statistically significant increase in the incidence of total major bleeding in the ticagrelor group by both study criteria $(11.6 \%$ versus $11.2 \%$; HR $=1.04 ; 95 \%$ CI: $0.95-1.13 ; P=0.43)$ and TIMI criteria $(7.9 \%$ versus 7.7\%; HR=1.03; 95\% CI: $0.93-1.15 ; P=0.57)$. On a subset analysis, no increase in CABG-related major bleeding was found in the ticagrelor group by either criterion. However, a statistically significant increase in the incidence of nonCABG-related major bleeding was found in the ticagrelor group (4.5\% versus $3.8 \%$; $\mathrm{HR}=1.19 ; 95 \% \mathrm{CI}$ : $1.02-1.38$; $P=0.03$ by study criteria; and $2.8 \%$ versus $2.2 \% ; \mathrm{HR}=1.25$; 95\% CI: $1.03-1.53 ; P=0.03$ by TIMI criteria).
Treatment with ticagrelor, like aspirin, was associated with a statistically significant reduction in all-cause mortality (4.5\% versus 5.9\%; HR=0.78, 95\% CI: $0.69-0.89 ; P<0.001)$. This observation can be attributed to better efficacy, backed up by a superior pharmacological profile, without a concomitant increase in the rate of overall major bleeding. This definite survival benefit with ticagrelor is in stark contrast to the absence of such benefit with the other antiplatelet drugs like prasugrel and Gp IIb/IIIa inhibitors.

The encouraging results in clinical trials have been backed up by favorable pharmacological data. As opposed to thienopyridines, ticagrelor is a reversible $\mathrm{P} 2 \mathrm{Y}_{12}$ inhibitor: a factor that may have contributed to its better safety profile. Gurbel et al studied the pharmacology of ticagrelor in their two studies..$^{20,21}$ The ONSET/OFFSET study enrolled patients with stable coronary artery disease on aspirin therapy, and compared the pharmacology of ticagrelor with that of clopidogrel. ${ }^{20}$ The antiplatelet action of ticagrelor was found to be rapid (41\% inhibition of platelet aggregation at 30 minutes versus $8 \%$ with clopidogrel; $P<0.0001$ ) and more potent ( $90 \%$ of patients had $>70 \%$ inhibition of platelet aggregation at 2 hours versus $16 \%$ with clopidogrel; $P<0.0001$ ). Despite the greater antiplatelet effect, inhibition of platelet aggregation at 24 hours after the last dose was equal in both ticagrelor- and clopidogrel-treated patients, thereby implying faster offset of action. The RESPOND study, recruiting a similar patient population, compared the antiplatelet action of ticagrelor in clopidogrel responders and nonresponders. ${ }^{21}$ The antiplatelet effect of ticagrelor was found to be same in both these groups. Inhibition of platelet aggregation in nonresponders treated with ticagrelor was higher than those treated with clopidogrel, at all times $(P<0.05)$.

Armstrong et al explored another aspect of ticagrelor pharmacology in which it was shown to inhibit cellular uptake of adenosine via equilibrative nucleoside transporter $1 .{ }^{22}$ This potentially increases the local concentration of adenosine, which is a known inhibitor of platelet aggregation. This multipronged effect of ticagrelor on adenosine and ADP pharmacology may have contributed to the superior efficacy observed in clinical trials.

\section{Prasugrel versus ticagrelor}

As discussed previously, both prasugrel and ticagrelor have been found to have superior clinical efficacy as compared to clopidogrel, with a significantly increased risk of bleeding events with prasugrel. However, till date, no head-tohead comparison has been made between these two newer $\mathrm{P} 2 \mathrm{Y}_{12}$ inhibitors. A multicenter, randomized trial, ISAR 
REACT 5, is underway to compare prasugrel and ticagrelor in ACS patients with a planned invasive strategy and can help define the best option for $\mathrm{P} 2 \mathrm{Y}_{12}$ inhibition. ${ }^{23}$

In a pharmacodynamic study by Alexopoulos et al enrolling clopidogrel hypo-responders 24 hours post-PCI, ticagrelor was found to be superior to prasugrel. ${ }^{24}$ The primary endpoint of platelet reactivity was found to be significantly lower with ticagrelor (32.9 platelet reactivity units; 95\% CI: 18.7-47.2) as compared to prasugrel (101.3 platelet reactivity units; 95\% CI: 86.8-115.7).

\section{Timing of administering the second antiplatelet}

As mentioned before, dual antiplatelet therapy with aspirin and a $\mathrm{P} 2 \mathrm{Y}_{12}$ inhibitor has become the standard of care, with the 2013 ACC/AHA guidelines for STEMI recommending the use of a $\mathrm{P} 2 \mathrm{Y}_{12}$ inhibitor (clopidogrel, prasugrel, or ticagrelor) as a class I indication. ${ }^{25}$ However, no explicit recommendations have been made with respect to the timing of the second antiplatelet drug after aspirin. Administration of a loading dose of a $\mathrm{P} 2 \mathrm{Y}_{12}$ inhibitor both before and during primary PCI has been approved. Administration of early dual antiplatelet therapy (which is commonly practiced) has a logistic drawback in patients where the coronary anatomy upon catheterization is found to be non-amenable to PCI, thereby requiring emergency $\mathrm{CABG}$. Various studies have underlined the increased risk of postoperative bleeding with preoperative clopidogrel use. ${ }^{26,27}$ The previous guidelines recommended a minimum time period of 5 days after stopping the second antiplatelet drug (a $\mathrm{P} 2 \mathrm{Y}_{12}$ inhibitor) before considering emergency CABG ${ }^{28}$ The current guidelines have revised the minimum recommended time period to 24 hours. ${ }^{25}$

Kapetanakis et al proposed withholding the administration of clopidogrel until an angiogram is performed (thereby revealing the coronary anatomy) and the need for CABG is assessed. ${ }^{29}$ However, it has been argued that this strategy will deny optimum antiplatelet therapy in the majority of the patients who do not require surgery, especially in view of the slower onset of antiplatelet action of clopidogrel. In the CIPAMI trial, early clopidogrel administration in STEMI patients was found to have a lower incidence of composite endpoint (death, reinfarction, urgent target-vessel revascularization) as compared to clopidogrel administration after angiogram ( $3 \%$ versus $7 \% ; P=0.09) .{ }^{30}$ Another proposed strategy is to withhold the dual antiplatelet therapy before angiography, only in patients where the likelihood of CABG is high. A risk score to predict the need for CABG was designed by Sadanandan et $\mathrm{al}^{31}$ although its clinical applicability has been questioned. ${ }^{32}$
As the newer P2 $\mathrm{Y}_{12}$ inhibitors prasugrel and ticagrelor have a superior pharmacological profile compared to clopidogrel, this property can be exploited to devise novel therapeutic strategies. Marchini et al presented an algorithm in which dual antiplatelet therapy was withheld in patients requiring emergent cardiac catheterization if the anticipated delay from presentation to catheterization was less than 6 hours. ${ }^{33}$ Prasugrel was administered only after confirming the coronary anatomy during angiography and assessing the need for $\mathrm{CABG}$. The underlying rationale is that, because of the faster and more-potent antiplatelet action of prasugrel, this strategy will achieve an enhanced platelet inhibition within a similar or potentially faster timeframe compared to preprocedural clopidogrel therapy. Ticagrelor can potentially fit in this treatment strategy as well.

\section{Gp Ilb/Illa inhibitors}

Most of the earlier studies done on Gp IIb/IIIa inhibitors were in the pre-dual antiplatelet-therapy era and demonstrated a clinical benefit at a somewhat increased risk of bleeding. ${ }^{34,35}$ The FINESSE (Facilitated Intervention With Enhanced Reperfusion Speed to Stop Events) study enrolled STEMI patients undergoing PCI and randomized them to receive abciximab plus reteplase (combination facilitated PCI), abciximab (facilitated PCI), or placebo (primary PCI) before the procedure. ${ }^{36}$ There was no statistically significant clinical benefit with either facilitated or combination facilitated PCI, and each of these was associated with an increased risk of bleeding.

The results from the limited studies in which clopidogrel pretreatment was given showed questionable benefit and an increased bleeding risk. ${ }^{37}$ Arguments have thus been made to restrict the use of Gp IIb/IIIa inhibitors as a bailout strategy in face of intraprocedural complications during PCI (eg, distal embolization, no reflow phenomenon, etc). The same has been adopted in the European Society of Cardiology (ESC) guidelines. ${ }^{38}$

Of special interest is the meta-analysis performed by De Luca et al evaluating STEMI patients undergoing primary PCI. ${ }^{37}$ The analysis showed no mortality benefit after 30 days $(2.8 \%$ versus $2.9 \% ; P=0.75)$ and an increased risk of major bleeding ( $4.1 \%$ versus $2.7 \% ; P=0.0004)$ with Gp IIb/IIIa inhibitors. However, a significant relationship between patient risk profile and mortality benefit from Gp IIb/IIIa inhibitors was observed $(P=0.008)$, with higher-risk patients benefitting the most.

This notion is in line with the findings of the ISARREACT 2 trial in which clinical benefits of abciximab were observed in high-risk NSTEMI patients with elevated 
troponin levels. ${ }^{39}$ In these patients, the primary endpoint (death, MI, or urgent target-vessel revascularization within 30 days) in the abciximab group was $13.1 \%$ compared with $18.3 \%$ in the placebo group $(\mathrm{RR}=0.71 ; 95 \% \mathrm{CI}$ : $0.54-0.95$; $P=0.02)$. This benefit was not observed in patients without an elevated troponin level. This drives the rationale of restricting routine $\mathrm{Gp}$ IIb/IIIa inhibitor use to high-risk patients (eg, large anterior wall $\mathrm{MI}$ and/or large clot burden).

While some studies have shown benefit of intracoronary administration of abciximab, ${ }^{40,41}$ others have shown no benefit, ${ }^{42}$ and intracoronary Gp IIb/IIIa-inhibitor therapy remains a class IIb indication. ${ }^{43}$ A meta-analysis comparing the three Gp IIb/IIIa inhibitors in patients undergoing PCI for STEMI showed no difference in their efficacy and risk profiles. ${ }^{44}$ Although all three approved Gp IIb/IIIa inhibitors have been shown to have comparable benefits, abciximab has been studied the most and is hence commonly used.

\section{Protease-activated receptor I inhibitor: vorapaxar}

The most recent addition to antiplatelet drugs is vorapaxar, approved in May 2014. Protease-activated receptor 1 inhibition prevents thrombin-mediated platelet activation. It has been proposed that adding a plateletactivated receptor 1 inhibitor to the current standard of dual antiplatelet therapy may provide a more comprehensive platelet inhibition. This approval was based on the findings of the TRA $2^{\circ} \mathrm{P}$-TIMI 50 trial, which enrolled patients with a history of ACS on maintenance antiplatelet therapy. ${ }^{45}$ As compared to dual antiplatelet therapy, maintenance therapy with vorapaxar resulted in some reduction in primary outcomes of cardiovascular death, MI, or stroke $(8.1 \%$ versus 9.7\%; HR=0.80; 95\% CI: $0.72-0.89 ; P<0.0001)$ at the expense of an increased risk of bleeding (3.4\% versus $2.1 \%$; $\mathrm{HR}=1.61 ; 95 \% \mathrm{CI}: 1.31-1.97 ; P<0.0001)$.

\section{LMWHs versus UFH}

LMWHs boast certain practical advantages over UFH. Because of its favorable pharmacology, weight-adjusted enoxaparin has been shown to provide more stable and reliable anticoagulation without the need of laboratory monitoring. ${ }^{46}$ Enoxaparin, the most widely used LMWH, has been compared to heparin in various studies. The most prominent amongst these was the SYNERGY trial, which enrolled high-risk NSTEMI patients. ${ }^{47}$ The incidence of primary composite endpoint of all-cause death or nonfatal MI during the first 30 days was comparable in enoxaparin and heparin groups $(14.0 \%$ versus $14.5 \%$; odds ratio $=0.96$;
95\% CI: 0.86-1.06; $P=0.40$ ). Also, no differences in ischemic events during PCI were observed between the two groups. A statistically significant increase in TIMI major bleeding was observed with enoxaparin ( $9.1 \%$ versus $7.6 \% ; P=0.008)$, but GUSTO (Global Utilization of Streptokinase and t-PA for Occluded Arteries) severe bleeding rates were comparable in the two groups $(2.7 \%$ versus $2.2 \% ; P=0.08)$.

Cohen et al in their study showed that prerandomization anticoagulant therapy or switching from one anticoagulant to another at the time of randomization could have potentially influenced the endpoint analysis of the SYNERGY trial. ${ }^{48}$ In the subgroup analysis, it was found that patients receiving "consistent enoxaparin therapy" experienced fewer deaths or MI when compared to "consistent heparin therapy" (13.3\% versus $15.9 \%$; HR $=0.82 ; 95 \%$ CI: $0.72-0.94$; $P=0.004$; adjusted $P=0.041)$. However, an increased incidence of GUSTO severe bleeding was observed with consistent enoxaparin therapy $(2.9 \%$ versus $2.1 \% ; P=0.0465)$.

The more recently concluded ATOLL trial enrolling STEMI patients undergoing primary PCI showed encouraging results. ${ }^{49}$ Intravenous (IV) enoxaparin was found to reduce the primary endpoint (30-day incidence of death, complication of MI, procedure failure, or major bleeding) when compared to UFH ( $28 \%$ versus $34 \%$; RR $=0.83 ; 95 \%$ CI: $0.68-1.01 ; P=0.06)$, with no difference in the occurrence of major bleeding ( $5 \%$ versus $5 \% ; P=0.79)$. Another salient trial that deserves mention is the STEEPLE trial enrolling patients undergoing elective PCI, which interestingly showed a decreased incidence of non-CABG related bleeding in the first 48 hours with enoxaparin therapy compared to heparin (5.9\% versus $8.5 \%$; $95 \% \mathrm{CI}:-4.7$ to $-0.6 ; P=0.01){ }^{50}$

Based on the current data, enoxaparin seems to be more effective than UFH at the expense of a modest and questionable increase in the risk of bleeding. The other FDA-approved LMWHs dalteparin and tinzaparin have not been studied extensively for ACS. In the limited evidence available, both have been found to be clinically comparable or inferior to enoxaparin. ${ }^{51,52}$ Although dalteparin has been approved for use in unstable angina/NSTEMI, the data on its efficacy profile is not substantial. Tinzaparin has no role in ACS currently.

\section{Bivalirudin versus UFH}

Bivalirudin has emerged as the third viable option for anticoagulation in ACS. However, arguments on its safety and efficacy profile have been marked by intense controversy and debate. The most prominent amongst the earlier trials analyzing bivalirudin was the ACUITY trial published in $2004 .^{53}$ 
In this trial, patients with STEMI were enrolled and randomized to receive UFH/enoxaparin plus a Gp IIb/IIIa inhibitor, bivalirudin plus a Gp IIb/IIIa inhibitor, or bivalirudin alone. Bivalirudin monotherapy was found to be clinically noninferior to heparin plus Gp IIb/IIIa-inhibitor therapy. Moreover, a strong evidence of significantly lower risk of major bleeding was observed in the bivalirudin group as compared to the heparin plus Gp IIb/IIIa group (4\% versus 7\%; RR $=0.52 ; 95 \%$ CI: $0.40-0.66 ; P<0.0001)$. However, it is critical to note that when the bivalirudin plus Gp IIb/IIIainhibitor group was compared to the heparin plus Gp IIb/ IIIa-inhibitor group, both these groups were found to have similar rates of composite ischemic endpoint $(9 \%$ versus $8 \% ; P=0.16)$ and bleeding ( $8 \%$ versus $7 \% ; P=0.32)$.

The findings of clinical noninferiority and reduced bleeding risk with bivalirudin therapy versus heparin plus Gp IIb/IIIa-inhibitor therapy in the ACUITY trial was in line with the results obtained from the subsequent trials: ISARREACT 4 (enrolling NSTEMI patients undergoing PCI) and HORIZONS-AMI. The HORIZONS-AMI trial enrolled high-risk STEMI patients undergoing PCI. ${ }^{54}$ Bivalirudin when compared with heparin plus Gp IIb/IIIa-inhibitor therapy showed similar rates of MACE $(5.4 \%$ versus $5.5 \% ; P=0.95)$ but a decreased risk of major bleeding (4.9\% versus $8.3 \%$; $\mathrm{RR}=0.60 ; 95 \% \mathrm{CI}: 0.46-0.77 ; P<0.001)$. A reduction in death from cardiac causes at 30 days and all-cause mortality was also observed in the bivalirudin group owing to a significantly reduced risk of major bleeding. Of special note, however, was the finding of increased rate of acute ST in the bivalirudin group in the first 24 hours $(1.3 \%$ versus $0.3 \% ; P<0.001)$, but no significant increase in ST was shown to be present at 30 days $(2.5 \%$ versus $1.9 \% ; P=0.30)$.

It is imperative to note that in all clinical trials on bivalirudin discussed so far, the reduced bleeding risk was observed when it was compared to heparin plus routine Gp IIb/IIIa-inhibitor therapy. A series of trials with modified study design, all published after 2013, have introduced a whole new perspective on the current standing of bivalirudin. In the EUROMAX trial, STEMI patients undergoing PCI were enrolled and randomized to either test or control groups. ${ }^{55}$ The test group received bivalirudin, with $\mathrm{Gp} \mathrm{IIb/IIIa-inhibitor} \mathrm{use} \mathrm{restricted} \mathrm{to} \mathrm{bailout;} \mathrm{and} \mathrm{the} \mathrm{control}$ group received heparin/enoxaparin, with optional use of $\mathrm{Gp} \mathrm{IIb/IIIa} \mathrm{inhibitors} \mathrm{at} \mathrm{the} \mathrm{physician's} \mathrm{discretion.} \mathrm{Overall,}$ the rate of Gp IIb/IIIa-inhibitor use was differential: 11.5\% in the bivalirudin group and $69.1 \%$ in the control group.

The incidence of primary composite outcome of death or non-CABG related major bleeding at 30 days was lower in the bivalirudin group $(5.1 \%$ versus $8.5 \%$; RR=0.60; $95 \%$ CI: $0.43-0.82 ; P=0.001)$, as was the risk of major bleeding (2.6\% versus $6.0 \%$; RR $=0.43 ; 95 \%$ CI: $0.28-0.66 ; P<0.001)$. However, the incidence of MACE was similar in both bivalirudin and heparin groups (65\% versus $61 \%$; $R=1.09 ; 95 \%$ CI: $0.77-1.52 ; P=0.64)$. As noted in the HORIZONS-AMI trial, the risk of acute ST was significantly higher with bivalirudin $(1.1 \%$ versus $0.2 \%$; RR=6.11; 95\% CI: $1.37-27.24$; $P=0.007)$. All three $\mathrm{P} 2 \mathrm{Y}_{12}$ inhibitors were used alternatively in a similar proportion in both groups. Overall, the results of EUROMAX were positive and consistent with those of the previous trials.

In the BRAVE-4 trial, STEMI patients undergoing primary PCI were randomized to receive either prasugrel plus bivalirudin or clopidogrel plus heparin. ${ }^{56}$ Notably, the use of $\mathrm{Gp} \mathrm{IIb/IIIa} \mathrm{inhibitors} \mathrm{was} \mathrm{reserved} \mathrm{to} \mathrm{bailout} \mathrm{in} \mathrm{both}$ groups $(3.0 \%$ in the prasugrel plus bivalirudin group versus $6.1 \%$ in the clopidogrel plus heparin group). The primary composite endpoint (death, MI, unplanned revascularization, ST, stroke, or bleeding at 30 days) was similar in both the groups $(15.6 \%$ in the prasugrel plus bivalirudin group versus $14.5 \%$ in the clopidogrel plus heparin group; $\mathrm{RR}=1.09$; onesided 97.5\% CI: $0-1.79 ; P=0.680$ ). Bleeding according to HORIZONS-AMI definition was also similar (14.1\% in the prasugrel plus bivalirudin group versus $12.0 \%$ in the clopidogrel plus heparin group; $\mathrm{RR}=1.18$; 95\% CI: $0.74-1.88$; $P=0.543$ ). Thus, prasugrel plus bivalirudin therapy failed to show any safety or efficacy benefit in the BRAVE-4 trial. The trial was however stopped prematurely owing to slow recruitment, having enrolled only 548 of the 1,240 patients originally planned, and was thus underpowered to test its primary hypothesis.

The most recently published HEAT-PPCI trial recruited STEMI patients undergoing primary PCI randomized to receive either bivalirudin or heparin, with the use of Gp $\mathrm{IIb} / \mathrm{IIIa}$ inhibitors restricted to bailout in both groups. ${ }^{57} \mathrm{It}$ was the first major trial making a head-to-head comparison between bivalirudin and heparin with a nondifferential Gp $\mathrm{IIb} / \mathrm{III}$-inhibitor use in the two groups $(13 \%$ in the bivalirudin group versus $15 \%$ in the heparin group). Use of the various $\mathrm{P} 2 \mathrm{Y}_{12}$ inhibitors was also proportional in both groups, with ticagrelor being used the most (61\%). The incidence of primary composite outcome (all-cause mortality, cerebrovascular accident, reinfarction, or unplanned target lesion revascularization) was higher in the bivalirudin group compared to the heparin group $(8.7 \%$ versus $5.7 \%$; $R R=1.52$; 95\% CI: $1.09-2.13 ; P=0.01)$. Notably, the incidence of major bleeding was similar in both groups $(3.5 \%$ in the bivalirudin 
group versus $3.1 \%$ in the heparin group; $\mathrm{RR}=1.15 ; 95 \%$ CI: $0.70-1.89 ; P=0.59$ ). Similar to the HORIZONS-AMI and EUROMAX trials, the incidence of ST was found to be significantly higher with bivalirudin (3.4\% versus $0.9 \%$; $\mathrm{RR}=3.91 ; 95 \%$ CI: $1.6-9.5 ; P=0.001)$.

In light of this new information, the role of bivalirudin is being revisited. Although the earlier trials showed a decreased risk of bleeding with bivalirudin, the latest data argues that this finding may have been attributed to differential use of Gp IIb/IIIa inhibitors in the two trial groups. Furthermore, there is substantial evidence of increased risk of ST with bivalirudin as compared to heparin. An overview of the current evidence on bivalirudin is presented in Table 2.

\section{Fondaparinux: current status}

Although trials evaluating fondaparinux have shown clinical benefit, the major drawback has been the substantially increased risk of catheter-related thrombosis. Hence, the current guidelines recommend against using fondaparinux monotherapy to support PCI (class III indication). ${ }^{43}$ For instance, in the OASIS 6 trial enrolling patients with STEMI, the rate of guiding catheter-related thrombosis was significantly higher in patients receiving fondaparinux ( 0 versus $22 ; P<0.001) .{ }^{58}$

\section{The oral anticoagulants (rivaroxaban, apixaban, dabigatran)}

There is no role of long-term use of oral anticoagulants (like rivaroxaban, apixaban, dabigatran) as maintenance therapy for ACS as per the current guidelines, but their utility has been explored. ${ }^{59}$ Most promising has been the results of the ATLAS ACS 2-TIMI 51 trial enrolling stabilized ACS patients within 7 days of hospitalization. ${ }^{60}$ The patients were randomized to either rivaroxaban therapy $(2.5 \mathrm{mg}$ or $5.0 \mathrm{mg}$ ), or placebo. Incidence of composite primary endpoint of death from cardiovascular causes, MI, or stroke in these three groups was $9.1 \%, 8.8 \%$, and $10.7 \%$, respectively (HR for rivaroxaban combined $=0.84 ; 95 \%$ CI: $0.75-0.96$; $P=0.008)$. The incidence of TIMI major bleeding not associated with CABG was $1.8 \%, 2.4 \%$, and $0.6 \%$, respectively (HR for rivaroxaban combined $=3.96$; 95\% CI: $2.46-6.38$; $P<0.001)$. Thus, the better efficacy outcomes were at a cost of increased risk of bleeding. FDA approval was declined based on concerns over missing follow-up safety data and methodological issues with the trial. ${ }^{61}$

Results of the trials evaluating the other oral anticoagulants apixaban and dabigatran have not been encouraging. The APPRAISE-2 trial recruited patients with recent ACS

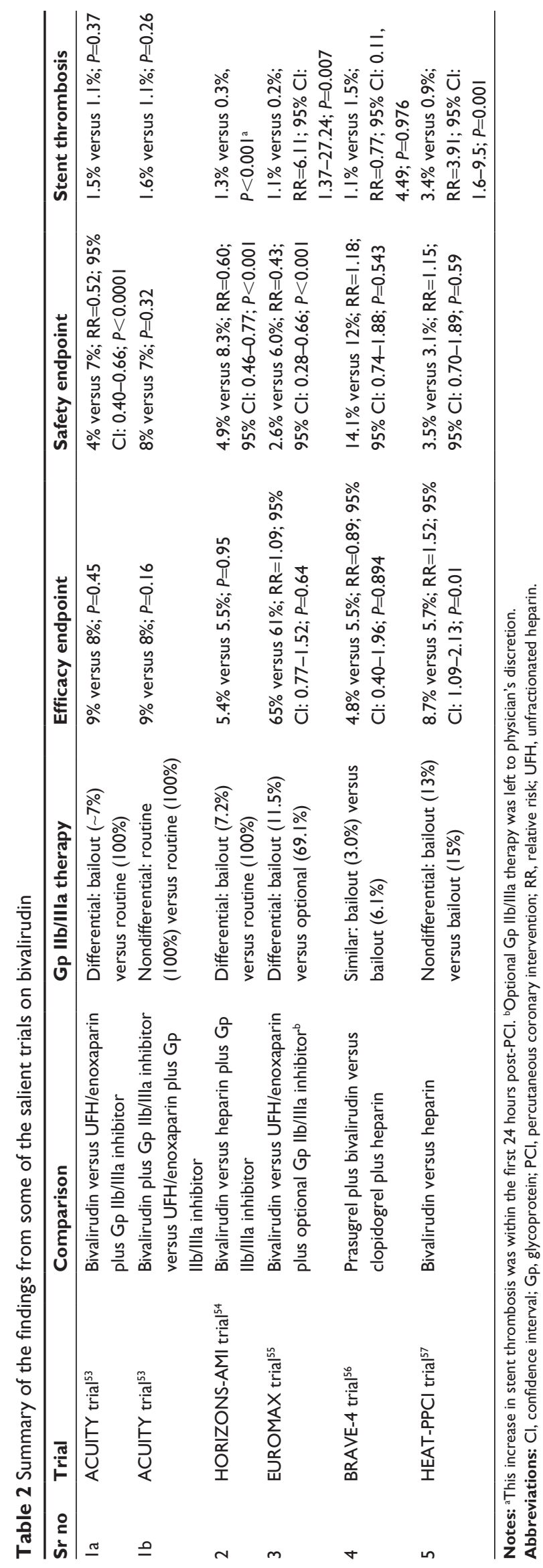


(within the previous 7 days) who were randomized to receive either apixaban or placebo as maintenance therapy. ${ }^{62}$ The trial was terminated prematurely because of strong evidence of increased risk of TIMI major bleeding in the apixaban group ( $1.3 \%$ versus $0.5 \% ; \mathrm{HR}=2.59 ; 95 \% \mathrm{CI}: 1.50-4.46 ; P=0.001)$ and no reduction in ischemic events $(7.5 \%$ versus $7.9 \%$; $\mathrm{HR}=0.95 ; 95 \% \mathrm{CI}: 0.80-1.11 ; P=0.51)$.

The RE-DEEM trial also recruited patients with recent ACS and randomized them to receive various doses of dabigatran $\left(50 \mathrm{mg}, 75 \mathrm{mg}, 110 \mathrm{mg}, 150 \mathrm{mg}\right.$ ) or placebo. ${ }^{63}$ A dosedependent increase in major or minor bleeding was observed with dabigatran (HR for $150 \mathrm{mg}$ group: 4.27; 95\% CI: 1.86-9.81). There was no significant reduction in the rate of ischemic events with dabigatran (3.8\% with placebo, $4.6 \%$ with $50 \mathrm{mg}$ dose, $4.9 \%$ with $75 \mathrm{mg}$ dose, $3.0 \%$ with $110 \mathrm{mg}$ dose, and $3.5 \%$ with $150 \mathrm{mg}$ dose).

\section{Patients on long-term anticoagulation undergoing PCl: current status of the "triple therapy"}

Antithrombotic therapy in patients on long-term anticoagulation undergoing PCI (eg, patients with atrial fibrillation) presents with a unique therapeutic challenge. Conventionally, patients are treated with dual antiplatelet therapy in addition to an oral anticoagulant as maintenance therapy after PCI (also known as triple oral antithrombotic therapy). This approach has been marked by the dilemma of increased bleeding risk with triple therapy versus ischemic risk without it, as reviewed by Reed and Cannon. ${ }^{64}$

The first major trial addressing this issue was the WOEST trial completed recently, which enrolled patients on warfarin undergoing PCI and randomized them to receive either triple therapy or clopidogrel plus warfarin. ${ }^{65}$ The primary endpoint of bleeding within 1 year of PCI was significantly lower in the double therapy group compared to the triple therapy group $(19.4 \%$ versus $44.4 \%$; $\mathrm{HR}=0.36$; 95\% CI: $0.26-0.50 ; P<0.0001)$. The secondary endpoint of death, MI, stroke, systemic embolization, and targetvessel revascularization was somewhat lower in the double therapy group $(11.3 \%$ versus $17.7 \%$; HR $=0.60 ; 95 \% \mathrm{CI}$ : $0.38-0.94 ; P=0.025)$. In a subgroup analysis, uninterrupted oral anticoagulation therapy during PCI was not associated with an increase in bleeding or major adverse cardiac and cerebrovascular events compared to the conventional heparin-bridging therapy. ${ }^{66}$

In spite of these new developments, more evidence is needed to form definite conclusions in this regard. Of note, the most recent $\mathrm{ACC} / \mathrm{AHA}$ guidelines on atrial fibrillation has assigned a class IIb recommendation to the use of clopidogrel plus oral anticoagulants (without aspirin) for the maintenance therapy of atrial fibrillation patients who have undergone coronary revascularization. ${ }^{67}$ Conclusion of some of the ongoing trials will provide more evidence in this regard. ${ }^{68}$

A decision tree depicting the current trends in interventional pharmacology is illustrated in Figure 3.

\section{Future directions}

The pharmacology of hemostasis and thrombosis is an ever-evolving field, and many more novel antiplatelet and anticoagulant drugs are being developed and tested. A brief overview of some of the important drugs under trial is presented below.

\section{Upcoming antiplatelet drugs IV P2Y ${ }_{12}$ inhibitors}

Among the most important upcoming antiplatelet drugs are the reversible IV $\mathrm{P}_{2} \mathrm{Y}_{12}$ inhibitors: cangrelor and elinogrel. The earlier Phase III trials CHAMPION PLATFORM and CHAMPION PCI failed to show clinical benefit of cangrelor use during PCI. ${ }^{69,70}$ However, encouraging results were obtained in the most recent CHAMPION PHOENIX trial, which enrolled patients undergoing urgent or elective PCI randomized to receive cangrelor or clopidogrel before PCI. ${ }^{71}$ The cangrelor group then received clopidogrel after the infusion was complete. The rate of primary composite endpoint of death, MI, ischemia-driven revascularization, or ST at 48 hours was lower in the cangrelor group $(4.7 \%$ versus $5.9 \%$; $\mathrm{RR}=0.78 ; 95 \% \mathrm{CI}: 0.66-0.93 ; P=0.005)$. There was no significant increase in severe bleeding with cangrelor $(0.16 \%$ versus $0.11 \%$; odds ratio $=1.50 ; 95 \%$ CI: $0.53-4.22$; $P=0.44)$.

The contradictory findings of the CHAMPION trials have been attributed to different definitions of periprocedural MI. $\mathrm{A}$ reduction in the rate of periprocedural MI accounted for most of the benefits of cangrelor observed in the CHAMPION PHOENIX trial (3.8\% versus $4.7 \%$; RR $=0.80$; $95 \%$ CI: $0.67-$ $0.97 ; P=0.02$ ), whereas the same outcome was responsible for its failure in the previous trials. It has been argued that the definition of periprocedural MI in the previous studies did not allow for discrimination between reinfarction and biomarkerpositive ACS: an issue that was supposedly addressed in the CHAMPION PHOENIX trial. ${ }^{71}$ The FDA however declined to approve cangrelor because of inconclusive evidence. ${ }^{72}$

Elinogrel is the only $\mathrm{P} 2 \mathrm{Y}_{12}$ inhibitor available for both oral and IV routes of administration. This gives it a unique 


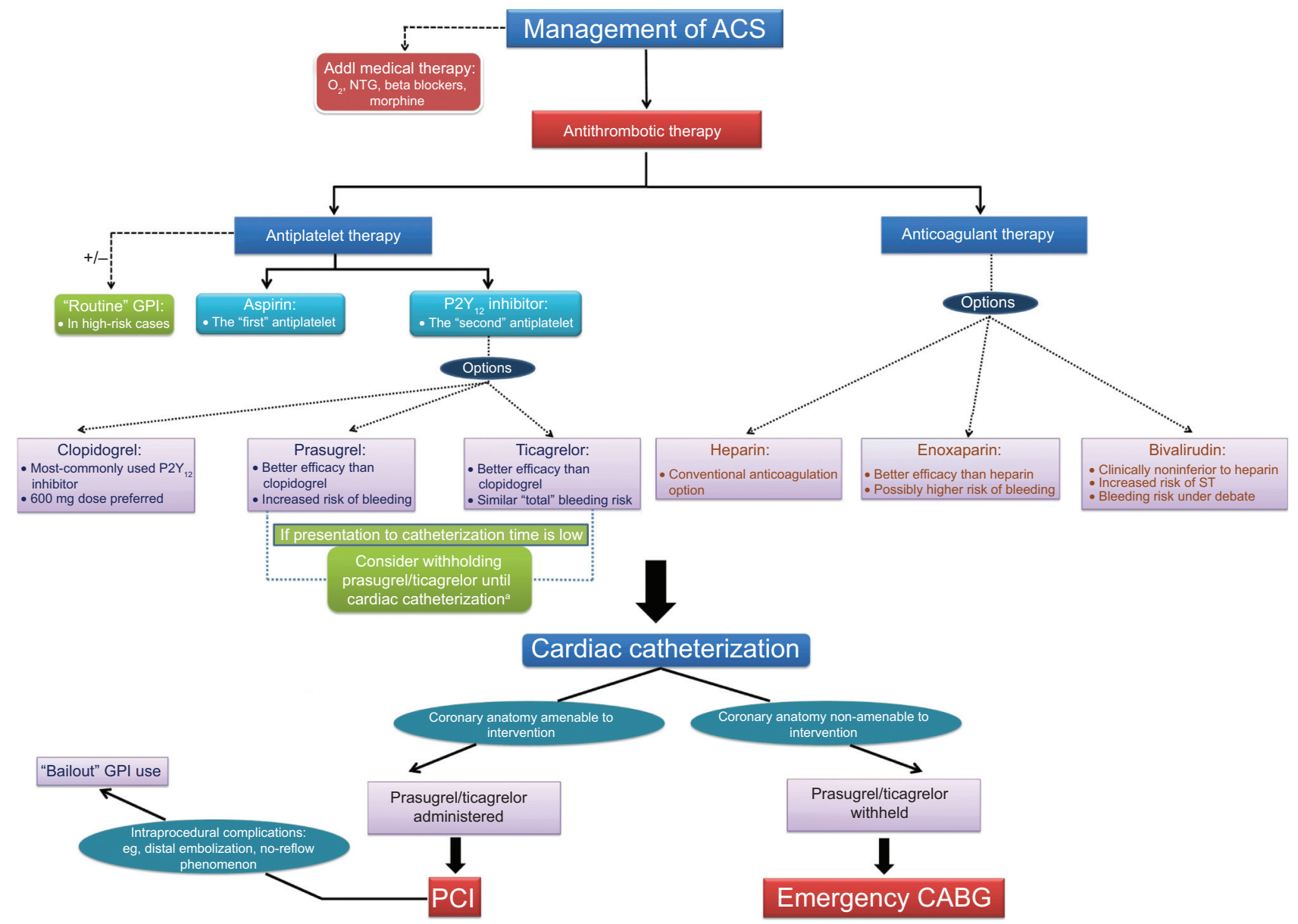

Figure 3 A decision tree depicting the various therapeutic options available for the management of ACS, and highlighting their unique characteristics based on the current evidence.

Notes: ${ }^{\mathrm{A}} \mathrm{A}$ strategy for the timing of introducing the second antiplatelet drug (a newer $\mathrm{P}^{2} \mathrm{Y}_{12}$ inhibitor - prasugrel or ticagrelor): modified from the algorithm proposed by Marchini et al..$^{33}$

Abbreviations: ACS, acute coronary syndrome; Addl, additional; CABG, coronary artery bypass grafting; GPI, glycoprotein Ilb/llla inhibitor; NTG, nitroglycerine; $\mathrm{O}_{2}$, oxygen; $\mathrm{PCl}$, percutaneous coronary intervention; ST, stent thrombosis.

pharmacological advantage over cangrelor, where an IV dose during PCI can be followed by an oral dose for a smooth transition of the antiplatelet effect. IV administration of cangrelor has to be followed by administration of another oral $\mathrm{P} 2 \mathrm{Y}_{12}$ inhibitor (like clopidogrel). This in turn raises the issue of drug interaction, as studied by Steinhubl et al. ${ }^{73}$ However, the results of the Phase II trial INNOVATE-PCI were equivocal, with similar efficacy endpoints and no increase in TIMI major/minor bleeding observed with elinogrel. ${ }^{74}$ No Phase III trials have been planned as of now.

An important clinical benefit of these IV P2 $\mathrm{Y}_{12}$ inhibitors is their quick onset of action and a short half-life. They can have a unique advantage for use in patients undergoing emergency CABG. Due to their quick offset of action, surgery can be safely performed within a few hours of stopping the drug. The BRIDGE trial enrolled patients undergoing planned CABG, and tested the use of cangrelor 1-6 hours before surgery. ${ }^{75}$ Platelet reactivity throughout the treatment period was lower with cangrelor than placebo (platelet reactivity units $<240$ throughout infusion in $98.8 \%$ versus $19.0 \%$ of patients; RR=5.2; 95\% CI: $3.3-8.1 ; P<0.001$ ). After discontinuation of cangrelor 1-6 hours before surgery, platelet reactivity was found to be similar in both groups (mean \pm 1 standard deviation platelet reactivity unit values: $279.7 \pm 106.5$ in cangrelor group versus $297.8 \pm 67.3$ in placebo group; $P=0.212$ ). Rates of CABG-related bleeding were similar with cangrelor and placebo groups ( $11.8 \%$ versus $10.4 \%$; $\mathrm{RR}=1.1 ; 95 \% \mathrm{CI}: 0.5-2.5 ; P=0.763)$. Thus, the findings of the trial supported this idea.

\section{Upcoming anticoagulant drugs Engineered LMWH}

M118 (also referred to as "adomiparin sodium" in some texts) is a novel LMWH with the desirable attributes of both enoxaparin and UFH. It has shown potent activity against both factors Xa and IIa, and is thereby easily monitored by a 
Table 3 List of clinical trials in order of their mention in the review

\begin{tabular}{|c|c|}
\hline I CURRENT/OASIS7 trial $^{7}$ & I6 BRAVE-4 trial| ${ }^{56}$ \\
\hline 2 ALBION trial ${ }^{12}$ & 17 HEAT-PPCI trial $\left.\right|^{57}$ \\
\hline 3 TRITON-TIMI 38 trial $^{16}$ & 18 OASIS 6 trial $^{58}$ \\
\hline 4 PLATO trial ${ }^{19}$ & 19 ATLAS ACS 2-TIMI 5 I trial ${ }^{60}$ \\
\hline 5 ISAR REACT 5 trial $^{23}$ & 20 APPRAISE- 2 trial $^{62}$ \\
\hline 6 CIPAMI trial ${ }^{30}$ & 2I RE-DEEM trial ${ }^{63}$ \\
\hline 7 FINESSE trial ${ }^{36}$ & 22 WOEST trial ${ }^{65}$ \\
\hline 8 ISAR-REACT 2 trial $^{39}$ & $23 \mathrm{CHAMPION}$ PLATFORM trial ${ }^{6{ }^{6}}$ \\
\hline 9 TRA $2^{\circ} \mathrm{P}-\mathrm{TIMI} 50$ trial $^{45}$ & 24 CHAMPION PCI trial ${ }^{70}$ \\
\hline 10 SYNERGY trial ${ }^{47}$ & 25 CHAMPION PHOENIX trial' \\
\hline II ATOLL trial ${ }^{49}$ & 26 INNOVATE-PCI trial ${ }^{74}$ \\
\hline 12 STEEPLE trial $\left.\right|^{50}$ & 27 BRIDGE trial ${ }^{75}$ \\
\hline I3 ACUITY trial ${ }^{53}$ & 28 EMINENCE trial ${ }^{76}$ \\
\hline I4 HORIZONS-AMI trial| ${ }^{54}$ & 29 REVERSAL-PCI trial ${ }^{77}$ \\
\hline 15 EUROMAX trial ${ }^{55}$ & \\
\hline
\end{tabular}

point-of-care assay. It has predictable pharmacokinetics with both subcutaneous and IV routes and can be easily reversed by protamine sulfate. M118 is being tested for use in ACS and has so far successfully completed a Phase II trial called the EMINENCE trial (enrolling patients undergoing elective $\mathrm{PCI}){ }^{76} \mathrm{M} 118$ was found to be clinically noninferior to heparin at preventing PCI-related complications, and the adverse event profiles of M118 and UFH were found to be comparable.

\section{RNA aptamers}

RNA aptamers are single-stranded oligonucleotide sequences that bind to certain protein sequences with high specificity. Since these are nucleotides, their complementary sequences can be engineered and used as very effective antidotes. One such anticoagulation system being tested for use with PCI is the REG 1 system, which inhibits factor IXa. In a successfully completed Phase II trial, REVERSAL-PCI, the REG 1 system was compared with UFH. ${ }^{77}$ Anticoagulation was partially reversed after PCI and fully reversed 4 hours later. This was in an attempt to achieve adequate intraprocedural anticoagulation, with rapid and effective reversal after the PCI. This system is currently being studied in a Phase III trial. $^{78}$ This novel strategy of the REG 1 system is certainly a hallmark of the innovations being made in this field.

A list of all the trials investigated and discussed in this review is presented in Table 3 .

\section{Conclusion}

There should be no doubt in saying that these are the most exciting times in this part of the world of pharmacotherapeutics. With advances in the understanding of basic mechanisms of hemostasis and thrombosis, ingenious molecular targets are being exploited, and many of these theoretical hypotheses have been translated into success in clinical trials. It has become imperative for the clinician to be well versed with all the current evidence available and adapt that knowledge in making day-to-day decisions. The need for individualization of therapy is being stressed. A couple of decades ago, the clinician did not have much to choose from; now, there is a plethora of options available. A sound knowledge of the current evidence on these drugs can help make rational decisions.

The most-recently approved $\mathrm{P} 2 \mathrm{Y}_{12}$ inhibitor ticagrelor seems to be superior to other $\mathrm{P}_{2} \mathrm{Y}_{12}$ inhibitors as it has been shown to be more effective than clopidogrel with no increase in total bleeding risk (although an increase in the risk of non-CABG-related bleeding was observed). However, we need to wait for the conclusion of the ongoing trial to make a more direct comparison between prasugrel and ticagrelor. Routine use of Gp IIb/IIIa inhibitors can be made in high-risk patients, while their use in other patients should be reserved to bailout. Enoxaparin has been found to be more efficacious but somewhat less safe than heparin, whereas the role of bivalirudin is being debated.

With this myriad of options available and more on their way, these innovations should be celebrated as an opportunity to practice better medicine.

\section{Disclosure}

The authors report no conflicts of interest in this work.

\section{References}

1. FDA approved Drug Products [webpage on the Internet]. Silver Spring: U.S. Food and Drug Administration. Available from: http://www. accessdata.fda.gov/Scripts/cder/drugsatfda/index.cfm. Accessed May 21, 2014.

2. ACC/AHA Joint Guidelines. Dallas: American Heart Association; 2014. Available from: http://my.americanheart.org/professional/Statements Guidelines/ByTopic/TopicsA-C/ACCAHA-Joint-Guidelines_UCM_ 321694_Article.jsp. Accessed July 27, 2014.

3. Lijfering WM, Flinterman LE, Vandenbroucke JP, Rosendaal FR, Cannegieter SC. Relationship between venous and arterial thrombosis: a review of the literature from a causal perspective. Semin Thromb Hemost. 2011;37(8):885-896.

4. Spbieszcyk P, Fishbein MC, Goldhaber SZ. Acute pulmonary embolism. don't ignore the platelet. Circulation. 2002;106:1748-1749.

5. Yusuf S, Zhao F, Mehta SR, et al. Effects of clopidogrel in addition to aspirin in patients with acute coronary syndromes without ST-segment elevation. N Engl J Med. 2001;345(7):494-502.

6. Chen ZM, Jiang LX, Chen YP, et al. Addition of clopidogrel to aspirin in 45,852 patients with acute myocardial infarction: randomised placebocontrolled trial. Lancet. 2005;366(9497):1607-1621.

7. CURRENT-OASIS 7 Investigators Mehta SR, Bassand JP, et al. Dose comparisons of clopidogrel and aspirin in acute coronary syndromes. N Engl J Med. 2010;363(10):930-942.

8. Patti G, Colonna G, Pasceri V, Pepe LL, Montinaro A, Di Sciascio G. Randomized trial of high loading dose of clopidogrel for reduction of periprocedural myocardial infarction in patients undergoing coronary intervention: results from the ARMYDA-2 (Antiplatelet therapy for Reduction of MYocardial Damage during Angioplasty) study. Circulation. 2005;111(16):2099-2106. 
9. Dangas G, Mehran R, Guagliumi G, et al. Role of clopidogrel loading dose in patients with ST-segment elevation myocardial infarction undergoing primary angioplasty: results from the HORIZONS-AMI (harmonizing outcomes with revascularization and stents in acute myocardial infarction) trial. J Am Coll Cardiol. 2009;54(15): $1438-1446$.

10. Siller-Matula JM, Huber K, Christ G, et al. Impact of clopidogrel loading dose on clinical outcome in patients undergoing percutaneous coronary intervention: a systematic review and meta-analysis. Heart. 2011;97:98-105.

11. von Beckerath N, Taubert D, Pogatsa-Murray G, Schömig E, Kastrati A, Schömig A. Absorption, metabolization, and antiplatelet effects of 300-, 600-, and 900-mg loading doses of clopidogrel: results of the ISAR-CHOICE (Intracoronary Stenting and Antithrombotic Regimen: Choose Between 3 High Oral Doses for Immediate Clopidogrel Effect) Trial. Circulation. 2005;112(19):2946-2950.

12. Montalescot G, Sideris G, Meuleman C, et al. A randomized comparison of high clopidogrel loading doses in patients with non-ST-segment elevation acute coronary syndromes: the ALBION (Assessment of the Best Loading Dose of Clopidogrel to Blunt Platelet Activation, Inflammation and Ongoing Necrosis) trial. $J$ Am Coll Cardiol. 2006; 48(5):931-938.

13. Serebruany VL, Steinhubl SR, Berger PB, Malinin AI, Bhatt DL, Topol EJ. Variability in platelet responsiveness to clopidogrel among 544 individuals. J Am Coll Cardiol. 2005;45(2):246-251.

14. Hagihara K, Kazui M, Kurihara A, et al. A possible mechanism for the differences in efficiency and variability of active metabolite formation from thienopyridine antiplatelet agents, prasugrel and clopidogrel. Drug Metab Dispos. 2009;37(11):2145-2152.

15. Brandt JT, Close SL, Iturria SJ, et al. Common polymorphisms of CYP2C19 and CYP2C9 affect the pharmacokinetic and pharmacodynamic response to clopidogrel but not prasugrel. J Thromb Haemost. 2007;5(12):2429-2436.

16. Wiviott SD, Braunwald E, McCabe $\mathrm{CH}$, et al. Prasugrel versus clopidogrel in patients with acute coronary syndromes. N Engl J Med. 2007; 357(20):2001-2015.

17. Brandt JT, Payne CD, Wiviott SD, et al. A comparison of prasugrel and clopidogrel loading doses on platelet function: magnitude of platelet inhibition is related to active metabolite formation. Am Heart $J$. 2007;153(1):66.e9-e16.

18. Jernberg T, Payne CD, Winters KJ, et al. Prasugrel achieves greater inhibition of platelet aggregation and a lower rate of non-responders compared with clopidogrel in aspirin-treated patients with stable coronary artery disease. Eur Heart J. 2006;27(10):1166-1173.

19. Wallentin L, Becker RC, Budaj A, et al. Ticagrelor versus clopidogrel in patients with acute coronary syndromes. $N$ Engl J Med. 2009; 361(11):1045-1057.

20. Gurbel PA, Bliden KP, Butler K, et al. Randomized double-blind assessment of the ONSET and OFFSET of the antiplatelet effects of ticagrelor versus clopidogrel in patients with stable coronary artery disease: the ONSET/OFFSET study. Circulation. 2009;120(25):2577-2585.

21. Gurbel PA, Bliden KP, Butler K, et al. Response to ticagrelor in clopidogrel nonresponders and responders and effect of switching therapies: the RESPOND study. Circulation. 2010;121(10):1188-1199.

22. Armstrong D, Summers C, Ewart L, Nylander S, Sidaway JE, van Giezen JJ. Characterization of the adenosine pharmacology of ticagrelor reveals therapeutically relevant inhibition of equilibrative nucleoside transporter 1. J Cardiovasc Pharmacol Ther. 2014;19(2): 209-219.

23. Schulz S, Angiolillo DJ, Antoniucci D, et al. Randomized comparison of ticagrelor versus prasugrel in patients with acute coronary syndrome and planned invasive strategy - design and rationale of the iNtracoronary Stenting and Antithrombotic Regimen: Rapid Early Action for Coronary Treatment (ISAR-REACT) 5 trial. J Cardiovasc Transl Res. 2014;7(1):91-100.
24. Alexopoulos D, Galati A, Xanthopoulou I, et al. Ticagrelor versus prasugrel in acute coronary syndrome patients with high onclopidogrel platelet reactivity following percutaneous coronary intervention: a pharmacodynamic study. J Am Coll Cardiol. 2012;60(3): 193-199.

25. O'Gara PT, Kushner FG, Ascheim DD, et al. 2013 ACCF/AHA guideline for the management of ST-elevation myocardial infarction: a report of the American College of Cardiology Foundation/American Heart Association Task Force on Practice Guidelines. Circulation. 2013;127:e362-e425.

26. Yende S, Wunderink RG. Effect of clopidogrel on bleeding after coronary artery bypass surgery. Crit Care Med. 2001;29(12):2271-2275.

27. Hongo RH, Ley J, Dick SE, Yee RR. The effect of clopidogrel in combination with aspirin when given before coronary artery bypass grafting. J Am Coll Cardiol. 2002;40(2):231-237.

28. Antman EM, Hand M, Armstrong PW, et al. 2007 Focused Update of the ACC/AHA 2004 Guidelines for the Management of Patients With ST-Elevation Myocardial Infarction: a report of the American College of Cardiology/American Heart Association Task Force on Practice Guidelines: developed in collaboration With the Canadian Cardiovascular Society endorsed by the American Academy of Family Physicians: 2007 Writing Group to Review New Evidence and Update the ACC/AHA 2004 Guidelines for the Management of Patients With ST-Elevation Myocardial Infarction, Writing on Behalf of the 2004 Writing Committee. Circulation. 2008;117(2):296-329.

29. Kapetanakis EI, Medlam DA, Boyce SW, et al. Clopidogrel administration prior to coronary artery bypass grafting surgery: the cardiologist's panacea or the surgeon's headache? Eur Heart J. 2005; 26(6):576-583.

30. Zeymer U, Arntz HR, Mark B, et al. Efficacy and safety of a high loading dose of clopidogrel administered prehospitally to improve primary percutaneous coronary intervention in acute myocardial infarction: the randomized CIPAMI trial. Clin Res Cardiol. 2012;101(4):305-312.

31. Sadanandan S, Cannon CP, Gibson CM, et al. A risk score to estimate the likelihood of coronary artery bypass surgery during the index hospitalization among patients with unstable angina and non-ST-segment elevation myocardial infarction. $J$ Am Coll Cardiol. 2004;44(4): 799-803.

32. Fitchett D, Eikelboom J, Fremes S, et al. Dual antiplatelet therapy in patients requiring urgent coronary artery bypass grafting surgery: a position statement of the Canadian Cardiovascular Society. Can J Cardiol. 2009;25(12):683-689. English; French.

33. Marchini J, Morrow D, Resnic F, et al. An algorithm for use of prasugrel (effient) in patients undergoing cardiac catheterization and percutaneous coronary intervention. Crit Pathw Cardiol. 2010;9(4):192-198.

34. Montalescot G, Barragan P, Wittenberg O, et al. Platelet glycoprotein $\mathrm{IIb} / \mathrm{III}$ inhibition with coronary stenting for acute myocardial infarction. N Engl J Med. 2001;344(25):1895-1903.

35. Antoniucci D, Migliorini A, Parodi G, et al. Abciximab-supported infarct artery stent implantation for acute myocardial infarction and long-term survival: a prospective, multicenter, randomized trial comparing infarct artery stenting plus abciximab with stenting alone. Circulation. 2004;109(14):1704-1706.

36. Ellis SG, Tendera M, de Belder MA, et al. Facilitated PCI in patients with ST-elevation myocardial infarction. $N$ Engl J Med. 2008; 358(21):2205-2217.

37. De Luca G, Navarese E, Marino P. Risk profile and benefits from Gp IIbIIIa inhibitors among patients with ST-segment elevation myocardial infarction treated with primary angioplasty: a meta-regression analysis of randomized trials. Eur Heart J. 2009;30(22):2705-2713.

38. Task Force on the management of ST-segment elevation acute myocardial infarction of the European Society of Cardiology (ESC); Steg PG, James SK, et al. ESC Guidelines for the management of acute myocardial infarction in patients presenting with ST-segment elevation. Eur Heart J. 2012;33(20):2569-2619. 
39. Kastrati A, Mehilli J, Neumann FJ, et al. Abciximab in patients with acute coronary syndromes undergoing percutaneous coronary intervention after clopidogrel pretreatment: the ISAR-REACT 2 randomized trial. JAMA. 2006;295(13):1531-1538.

40. Kakkar AK, Moustapha A, Hanley HG, et al. Comparison of intracoronary vs intravenous administration of abciximab in coronary stenting. Catheter Cardiovasc Interv. 2004;61(1):31-34.

41. Hansen PR, Iversen A, Abdulla J. Improved clinical outcomes with intracoronary compared to intravenous abciximab in patients with acute coronary syndromes undergoing percutaneous coronary intervention: a systematic review and meta-analysis. J Invasive Cardiol. 2010;22(6):278-282.

42. Bertrand OF, Rodés-Cabau J, Larose E, et al. Intracoronary compared to intravenous Abciximab and high-dose bolus compared to standard dose in patients with ST-segment elevation myocardial infarction undergoing transradial primary percutaneous coronary intervention: a two-by-two factorial placebo-controlled randomized study. $\mathrm{Am} \mathrm{J}$ Cardiol. 2010;105(11):1520-1527.

43. Levine GN, Bates ER, Blankenship JC, et al. 2011 ACCF/AHA/ SCAI Guideline for Percutaneous Coronary Intervention: a report of the American College of Cardiology Foundation/American Heart Association Task Force on Practice Guidelines and the Society for Cardiovascular Angiography and Interventions. Circulation. 2011;124: e574-e651.

44. Gurm HS, Tamhane U, Meier P, Grossman PM, Chetcuti S, Bates ER. A comparison of abciximab and small-molecule glycoprotein IIb/IIIa inhibitors in patients undergoing primary percutaneous coronary intervention: a meta-analysis of contemporary randomized controlled trials Circ Cardiovasc Interv. 2009;2(3):230-236.

45. Scirica BM, Bonaca MP, Braunwald E, et al. Vorapaxar for secondary prevention of thrombotic events for patients with previous myocardial infarction: a prespecified subgroup analysis of the TRA $2^{\circ} \mathrm{P}$-TIMI 50 trial. Lancet. 2012;380(9850):1317-1324.

46. Fareed J, Hoppensteadt D, Walenga J, et al. Pharmacodynamic and pharmacokinetic properties of enoxaparin: implications for clinical practice. Clin Pharmacokinet. 2003;42(12):1043-1057.

47. Ferguson JJ, Califf RM, Antman EM, et al. Enoxaparin vs unfractionated heparin in high-risk patients with non-ST-segment elevation acute coronary syndromes managed with an intended early invasive strategy: primary results of the SYNERGY randomized trial. JAMA. 2004;292(1):45-54.

48. Cohen M, Mahaffey KW, Pieper K, et al. A subgroup analysis of the impact of prerandomization antithrombin therapy on outcomes in the SYNERGY trial: enoxaparin versus unfractionated heparin in nonST-segment elevation acute coronary syndromes. J Am Coll Cardiol. 2006;48(7):1346-1354.

49. Montalescot G, Zeymer U, Silvain J, et al. Intravenous enoxaparin or unfractionated heparin in primary percutaneous coronary intervention for ST-elevation myocardial infarction: the international randomised open-label ATOLL trial. Lancet. 2011;378(9792): 693-703.

50. Montalescot G, Gallo R, White HD, et al. Enoxaparin versus unfractionated heparin in elective percutaneous coronary intervention 1-year results from the STEEPLE (SafeTy and efficacy of enoxaparin in percutaneous coronary intervention patients, an international randomized evaluation) trial. JACC Cardiovasc Interv. 2009;2(11):1083-1091.

51. Klein W, Buchwald A, Hillis SE, et al. Comparison of low-molecularweight heparin with unfractionated heparin acutely and with placebo for 6 weeks in the management of unstable coronary artery disease. Fragmin in unstable coronary artery disease study (FRIC). Circulation. 1997;96(1):61-68.

52. Katsouras C, Michalis LK, Papamichael N, et al. Enoxaparin versus tinzaparin in non-ST-segment elevation acute coronary syndromes: results of the enoxaparin versus tinzaparin (EVET) trial at 6 months. Am Heart J. 2005;150(3):385-391.
53. Stone GW, White HD, Ohman EM, et al. Bivalirudin in patients with acute coronary syndromes undergoing percutaneous coronary intervention: a subgroup analysis from the Acute Catheterization and Urgent Intervention Triage strategy (ACUITY) trial. Lancet. 2007; 369(9565):907-919.

54. Stone GW, Witzenbichler B, Guagliumi G, et al. Bivalirudin during primary PCI in acute myocardial infarction. $N$ Engl J Med. 2008; 358(21):2218-2230.

55. Steg PG, van 't Hof A, Hamm CW, et al. Bivalirudin started during emergency transport for primary PCI. N Engl J Med. 2013;369(23): 2207-2217.

56. Schulz S, Richardt G, Laugwitz KL, et al. Prasugrel plus bivalirudin vs clopidogrel plus heparin in patients with ST-segment elevation myocardial infarction. Eur Heart J. 2014;35(34):2285-2294.

57. Shahzad A, Kemp I, Mars C, et al. Unfractionated heparin versus bivalirudin in primary percutaneous coronary intervention (HEAT-PPCI): an open-label, single centre, randomised controlled trial. Lancet. In press 2014.

58. Yusuf S, Mehta SR, Chrolavicius S, et al. Effects of fondaparinux on mortality and reinfarction in patients with acute ST-segment elevation myocardial infarction: the OASIS-6 randomized trial. JAMA. 2006;295(13):1519-1530.

59. Sinnaeve PR, Adriaenssens T, Höchtl T, Huber K. New oral anticoagulant agents after ACS. Eur Heart J Acute Cardiovasc Care. 2012; 1(1):87-93.

60. Mega JL, Braunwald E, Wiviott SD, et al. Rivaroxaban in patients with a recent acute coronary syndrome. $N$ Engl J Med. 2012;366(1):9-19.

61. Rivaroxaban STEMI study hits print as FDA delivers setback: ATLAS ACS 2-TIMI 51 [article on the Internet]. Medscape; WebMD LLC; Mar 05, 2013. Available from: http://www.medscape.com/ viewarticle/791479. Accessed July 27, 2014.

62. Alexander JH, Lopes RD, James S, et al. Apixaban with antiplatelet therapy after acute coronary syndrome. $N$ Engl J Med. 2011; 365(8):699-708.

63. Oldgren J, Budaj A, Granger CB, et al. Dabigatran vs placebo in patients with acute coronary syndromes on dual antiplatelet therapy: a randomized, double-blind, phase II trial. Eur Heart J. 2011; 32(22):2781-2789.

64. Reed GW, Cannon CP. Triple oral antithrombotic therapy in atrial fibrillation and coronary artery stenting. Clin Cardiol. 2013; 36(10):585-594.

65. Dewilde WJ, Oirbans T, Verheugt FW, et al. Use of clopidogrel with or without aspirin in patients taking oral anticoagulant therapy and undergoing percutaneous coronary intervention: an open-label, randomised, controlled trial. Lancet. 2013;381(9872):1107-1115.

66. Dewilde WJ, Janssen PW, Kelder JC, et al. Uninterrupted oral anticoagulation versus bridging in patients with long-term oral anticoagulation during percutaneous coronary intervention: subgroup analysis from the WOEST trial. EuroIntervention. 2014;pii:20140202-08.

67. January CT, Wann LS, Alpert JS, et al. 2014 AHA/ACC/HRS Guideline for the Management of Patients With Atrial Fibrillation: A Report of the American College of Cardiology/American Heart Association Task Force on Practice Guidelines and the Heart Rhythm Society. Circulation. Epub 2014, Apr 10.

68. Janssen Scientific Affairs, LLC. A Study Exploring Two Strategies of Rivaroxaban (JNJ39039039; BAY-59-7939) and One of Oral Vitamin K Antagonist in Patients With Atrial Fibrillation Who Undergo Percutaneous Coronary Intervention (PIONEER AF-PCI). Available from: http://clinicaltrials.gov/show/NCT01830543. NLM identifier: NCT01830543. Accessed July 27, 2014.

69. Bhatt DL, Lincoff AM, Gibson CM, et al. Intravenous platelet blockade with cangrelor during PCI. N Engl J Med. 2009;361(24):2330-2341.

70. Harrington RA, Stone GW, McNulty S, et al. Platelet inhibition with cangrelor in patients undergoing PCI. N Engl J Med. 2009;361(24): $2318-2329$. 
71. Bhatt DL, Stone GW, Mahaffey KW, et al. Effect of platelet inhibition with cangrelor during PCI on ischemic events. $N$ Engl J Med. 2013; 368(14):1303-1313

72. FDA Advisory Panel Votes No on Approving Cangrelor for PCI, Bridge Therapy [article on the Internet]. Medscape; WebMD LLC; Feb 12, 2014. Available from: http://www.medscape.com/viewarticle/820567. Accessed July 27, 2014.

73. Steinhubl SR, Oh JJ, Oestreich JH, Ferraris S, Charnigo R, Akers WS. Transitioning patients from cangrelor to clopidogrel: pharmacodynamic evidence of a competitive effect. Thromb Res. 2008;121(4):527-534.

74. Welsh RC, Rao SV, Zeymer U, et al. A randomized, double-blind, active-controlled phase 2 trial to evaluate a novel selective and reversible intravenous and oral P2Y12 inhibitor elinogrel versus clopidogrel in patients undergoing nonurgent percutaneous coronary intervention: the INNOVATE-PCI trial. Circ Cardiovasc Interv. 2012;5(3):336-346.

75. Angiolillo DJ, Firstenberg MS, Price MJ, et al. Bridging antiplatelet therapy with cangrelor in patients undergoing cardiac surgery: a randomized controlled trial. JAMA. 2012;307(3):265-274.
76. Rao SV, Melloni C, Myles-Dimauro S, et al. Evaluation of a new heparin agent in percutaneous coronary intervention: results of the phase 2 evaluation of M118 IN pErcutaNeous Coronary intErvention (EMINENCE) Trial. Circulation. 2010;121(15):1713-1721.

77. Cohen MG, Purdy DA, Rossi JS, et al. First clinical application of an actively reversible direct factor IXa inhibitor as an anticoagulation strategy in patients undergoing percutaneous coronary intervention. Circulation. 2010;122(6):614-622.

78. Regado Biosciences, Inc. A Study To Determine the Efficacy and Safety of REG1 Compared to Bivalirudin in Patients Undergoing PCI (Regulate). Available from: http://clinicaltrials.gov/show/NCT01848106. NLM identifier: NCT01848106. Accessed July 27, 2014.

\section{Publish your work in this journal}

Therapeutics and Clinical Risk Management is an international, peerreviewed journal of clinical therapeutics and risk management, focusing on concise rapid reporting of clinical studies in all therapeutic areas outcomes, safety, and programs for the effective, safe, and sustained use of medicines. This journal is indexed on PubMed Central, CAS,
EMBase, Scopus and the Elsevier Bibliographic databases. The manuscript management system is completely online and includes a very quick and fair peer-review system, which is all easy to use. Visit http://www.dovepress.com/testimonials.php to read real quotes from published authors.

Submit your manuscript here: http://www.dovepress.com/therapeutics-and-clinical-risk-management-journal 